\title{
Comparative Analysis of Private Retail Community Pharmacies' Participation in the National Health Insurance Scheme of Nigeria and Ghana: Implications for Access to Essential Medicines
}

\section{Roland Nnaemeka Okoro ${ }^{1 *}$}

OPEN ACCESS

Citation: Roland Nnaemeka Okoro Comparative Analysis of Private Retail Community Pharmacies' Participation in the National Health Insurance Scheme of Nigeria and Ghana: Implications for Access to Essential Medicines. Ethiop J Health Sci. 2019;29(3):401.

doi:http://dx.doi.org/10.4314/ ejhs.v29i3.13

Received: October 23, 2018

Accepted: February 27, 2019

Published: May 1, 2019

Copyright: (C) 2019 Roland N.O. This is an open access article distributed under the terms of the Creative Commons Attribution License, which permits unrestricted use, distribution, and reproduction in any medium, provided the original author and source are credited. Funding: Nil

Competing Interests: The author declare that no competing interest exists. Affiliation and Correspondence:

${ }^{1}$ Department of Clinical Pharmacy and Pharmacy Administration Faculty of Pharmacy, University of Maiduguri. Maiduguri, Nigeria *Email: orolandn@gmail.com
ABSTRACT

BACKGROUND: Frequent stock-out of drugs in the public hospitals causes National Health Insurance Scheme (NHIS) enrollees to purchase most of their medicines out-of-pocket in community pharmacies, thereby imposing financial constraints on them against the main objective of the scheme. The objectives of this study were to determine and compare the level of participation of private retail community pharmacies (PRCPs) in the NHIS of Nigeria and Ghana, to describe their spatial distribution, and to highlight from literature major factors that would influence the participation of these pharmacies in the scheme.

METHODS: PRCPS data were collected from the Nigerian NHIS active secondary healthcare providers list of $1^{\text {st }}$ July 2017 and the Ghanaian NHIS active providers online list of 2018. PRCPS densities at the national levels were calculated from last published national coverage data for each country.

RESULTS: The total number of PRCP accredited by NHIS of both Nigeria and Ghana is 964(639[66.3\% versus 325[33.7\%]). NHIS accredited PRCPs densities for Nigeria and Ghana were 1 PRCP per 9, 390 enrollees and 1 PRCP per 33, 108 enrollees respectively. Across the Nigerian States, it was noted that Lagos State has the highest proportion $(21.4 \%, n=137)$ of community pharmacy participation in the scheme whereas, in Ghan, Greater Accra Region has the highest participation $(34.2 \%, n=111)$. CONCLUSION: This study revealed low participation of PRCPs and skewed spatial distribution between urban and rural areas of both countries, although there was higher participation of these pharmacies in Nigeria due to Nigerian lower NHIS coverage data compared to Ghana.

KEYWORDS: National Health Insurance Scheme (NHIS), Reimbursement, Essential Medicines, Private Retail Community Pharmacy (PRCP), Nigeria, Ghana

\section{INTRODUCTION}

Access to quality healthcare is a fundamental human right because of the enormous benefits it has on the individual and the economy of a nation. However, the major factor that has contributed to the poor performance of health systems of developing nations is limited access to health facilities (1) and access to affordable medicines. Those 
hardest hit are the poorest members of the population in these countries who purchase most medicines out-of-pocket. In recent years, there has been a trend for many developing countries including Nigeria and Ghana to move towards a new or expanded role for various forms of social health insurance, in the pursuit of universal healthcare coverage (UHC) as championed by the World Health Organization (2).

UHC using National Health Insurance Scheme (NHIS) as a tool will be difficult to achieve as long as access to health facilities and access to safe, effective, quality and affordable essential medicines for all citizens of a country remain limited. In particular, in the attainment of Sustainable Development Goals (SDGs) Number Three (good health and well being) by 2030 may be elusive agenda. SDGs now form an integral part of national development policy for Nigeria and Ghana as reflected in their SDGs reports $(3,4)$.

In Nigeria, NHIS was conceived as far back as 1962 (5). In terms of implementation, the National Council on Health approved re-packaging to ensure full private sector participation in the scheme and legislation was signed in May 1999 but was officially launched in 2005. Currently, it is built around three main sub-schemes to cater for different segments of the population: the Formal Sector Social Health Insurance Programmes, Informal Sector Social Health Insurance Programmes, Vulnerable Group Sector Social Health Insurance Programmes. Its principal aim is to secure universal coverage and access to adequate and affordable healthcare in order to improve the health status of Nigerians.

Ghana shares a similar post-independence history with Nigeria in terms of healthcare in the country (6). After independence in 1957, the Ghanaian Government also introduced a tax-based health financing system in which services were provided free at the point of use by the public sector. Ghana is the first African country to roll out NHIS. In 2001, the Ghanaian Government passed legislation which established its own NHIS in 2004 which is built around three types of health insurance scheme: the District Mutual Health Insurance Schemes, the Private Mutual Health
Insurance Schemes, and the Private Commercial Health Insurance Schemes with objective to ensure access to basic health care services to all residents of Ghana geared towards achieving universal coverage for the population as a whole.

Healthcare providers categorized into primary, secondary, and tertiary are one of the stakeholders of the NHIS in both countries. In Nigeria and Ghana, NHIS a private sector driven concept aims to build the capacity of private healthcare providers and increase access to private sector health services for the poor. In line with this policy, the national health insurance authorities of both countries accredit both private and public health facilities to provide services covered by the NHIS. Among private healthcare providers are community pharmacies that provide a secondary level of care.

The constantly low quality and inadequacy of health services provided in public facilities have made the private sector an unavoidable choice for consumers of healthcare in most developing nations. Therefore, community pharmacies are recognized as the most accessible healthcare facilities to the general public in many parts of the world, and their pharmacists are increasingly being recognized as a source of professional healthrelated advice (7). The mission of pharmacy practice especially, with respect to community pharmacy practice according to the International Pharmaceutical Federation (FIP), is to provide medicines, other healthcare products and services and to assist people and the public to make the optimal use of them. Community pharmacies also maintain links with other health professionals in the healthcare delivery system to ensure that patient outcomes are optimized. Despite being accessible healthcare facilities that provide valuable healthcare services to patients, they remain underutilized in the healthcare delivery systems of many developing nations.

Previous studies have revealed low participation of private retail community pharmacies (PRCPs) in the NHIS of both countries (8-10). These researchers who often focused on one state or region or district used questionnaires and/or focused-group discussions methods to

DOI: http://dx.doi.org/10.4314/ejhs.v29i3.13 
collect their data, which gained limited information on the level of involvement of PRCPs in NHIS of both countries. Therefore, this study proposes that in order to draw a more convincing conclusion on the level of participation, it is necessary to use national databases.

The aims of this study were to determine and compare the level of participation of PRCPs in the NHIS of Nigeria and Ghana, to describe their spatial distribution, and to highlight from literature the major factors that would influence the participation of these pharmacies in the implementation of the scheme. Ghana was selected as a comparator country for Nigeria because of similarities the two countries share in NHIS structure and implementation. The findings of this study will inform policy and intervention activities that will improve access to essential medicines in the scheme.

\section{METHODS}

Data source and data collection: The data for the study were obtained from the last updated Nigerian NHIS accredited secondary providers list (active secondary healthcare providers on $1^{\text {st }}$ July 2017) (11) and Ghanaian NHIS online list of active providers of 2018 (12). The data included the names of accredited PRCPs in Nigeria by States and Local Government Areas (LGAs) and in Ghana by Regions and Metropolitan, Municipal and District Assemblies (MMAs). The extracted data were entered into Microsoft ${ }^{\circledR}$ Excel 2007. PRCPs density (i.e. the number of enrollees serviced by one NHIS accredited PRCP) at the national levels were calculated from NHIS coverage data of 6 million for Nigeria as at 2017 (13) and 10.76 million for Ghana as at 2016 (14).

Data analysis: Descriptive statistics and basic spatial statistical (Geographic Information System) methods were applied to the data. Results were summarized using numbers, percentages, and ratio. Statistical Package for Social Sciences for Windows version 21 and Quantum Geographical Information System (QGIS) software for Windows version 2.18.24 were used for data analyses.

Ethical consideration: Ethical approval was obtained from the Research Review Board of the
Faculty of Pharmacy, University of Maiduguri, Nigeria.

\section{RESULTS}

The total number of PRCPs accredited by the NHIS of both Nigeria and Ghana is 964(639[66.3\%] versus 325[33.7\%]). The distribution of accredited PRCPs across each country is such that highest proportion $(21.4 \%, \mathrm{n}$ $=137$ ) falls under Lagos State of Nigeria and Greater Accra Region of Ghana $(34.2 \%, n=111)$.

On the other hand, Adamawa, Borno, Gombe, Yobe, and Taraba States of Nigeria and upper west region of Ghana have the least NHIS accredited retail community pharmacies $(0[0.0 \%]$ versus $3[0.9 \%])$ respectively. The results are presented in Table 1. Furthermore, the NHIS accredited PRCPs densities were 1 PRCP per 9, 390 enrollees for Nigeria and 1 PRCP per 33,108 enrollees for Ghana, respectively.

Spatial analysis results are presented in Figures $1 \mathrm{a}$ and $\mathrm{b}$. It was found that only 132 of 774 (17.1\%) LGAs in Nigeria had at least one NHIS accredited PRCP with Abuja Municipal Area Council having the highest number (69) followed by Kaduna North with 31 . LGAs with a number of NHIS accredited PRCPs between 15 and 28 are Amuwo-Odofi, Alimosho, Ibadan North, Ikeja, Obio/Akpor, and Surulere. Those that have between 1 and 14 accredited PRCPs are Afikpo North, Aguata, Ajerom/Ifelodun, Akure North, Ayedaade, Ethiope East, Ilesha West, Lagelu, Lagos Island, Olorunda, Oluyole, Ona_Ara, Onitsha South, Shomolu, Ughelli North, Aba North, Anaocha. Others are Ibadan North West, Idemili North, Ifako-Ijaye, Ilesha East, Nnewi North, Shomolu, Apapa, Gwagwalada, Mushin, Agege, Mainland, Ibadan South West, and Onitsha North. Detailed spatial distribution of NHIS accredited PRCPs in Nigeria is shown in Figure 1.

It was found that only 72 of $254(0.3 \%)$ MMAs in Ghana have at least one NHIS accredited PRCP. Manhyia, Ga, Bantama, Kpeshie, Sekondi-Takoradi Metropolitan, and Ablekuma local assemblies respectively have between 15 and 28 NHIS accredited PRCPs. Each of Asante Akim North, Kwabre, Atebubu, Agona,

DOI: http://dx.doi.org/10.4314/ejhs.v29i3.13 
Mfantseman, New Juaben, accredited PRCPs. Detailed spatial distribution of Suhum/Kraboa/Coaltar, Ashiedu Keteke, NHIS accredited PRCPs in the MMAs of Ghana Ayawaso, Dangme West among other local is shown in Figure $1 \mathrm{~b}$. assemblies have between 1 and 14 NHIS

Table 1: Distribution of NHIS accredited PRCPs in Nigeria $(\mathrm{N}=639)$ and Ghana $(\mathrm{N}=325)$.

\begin{tabular}{|c|c|c|c|}
\hline \multicolumn{2}{|c|}{ NIGERIA } & \multicolumn{2}{|c|}{ GHANA } \\
\hline & Community Pharmacy & & Community Pharmacy \\
\hline State & $\mathbf{n}(\%)$ & Region & $n(\%)$ \\
\hline Lagos & $137(21.4)$ & Greater Accra & $111(34.2 \%)$ \\
\hline Federal Capital Territory & $83(13.0)$ & Ashanti & $92(28.3 \%)$ \\
\hline Kaduna & $49(7.7)$ & Western & $30(9.2 \%)$ \\
\hline Оуо & $43(6.7)$ & Eastern & $23(7.1 \%)$ \\
\hline Rivers & $41(6.4)$ & Central & $21(6.5 \%)$ \\
\hline Plateau & $24(3.8)$ & Brong Ahafo & $18(5.5 \%)$ \\
\hline Anambra & $22(3.4)$ & Northern & $11(3.4 \%)$ \\
\hline Niger & $20(3.1)$ & Volta & $10(3.1 \%)$ \\
\hline Delta & $20(3.1)$ & Upper East & $6(1.8 \%)$ \\
\hline Enugu & $18(2.8)$ & Upper West & $3(0.9 \%)$ \\
\hline Imo & $15(2.3)$ & & \\
\hline Edo & $14(2.2)$ & & \\
\hline Ondo & $14(2.2)$ & & \\
\hline Benue & $12(1.9)$ & & \\
\hline Abia & $11(1.7)$ & & \\
\hline Ebonyi & $11(1.7)$ & & \\
\hline Sokoto & $10(1.6)$ & & \\
\hline Kogi & $9(1.4)$ & & \\
\hline Kwara & $9(1.4)$ & & \\
\hline Nasarawa & $9(1.4)$ & & \\
\hline Kano & $9(1.4)$ & & \\
\hline Bayelsa & $9(1.4)$ & & \\
\hline Ogun & $9(1.4)$ & & \\
\hline Bauchi & $8(1.3)$ & & \\
\hline Osun & $7(1.1)$ & & \\
\hline Cross River & $6(0.9)$ & & \\
\hline Zamfara & $5(0.8)$ & & \\
\hline Akwaibom & $5(0.8)$ & & \\
\hline Kastina & $4(0.6)$ & & \\
\hline Kebbi & $4(0.6)$ & & \\
\hline Ekiti & $2(0.3)$ & & \\
\hline Adamawa & $0(0.0)$ & & \\
\hline Borno & $0(0.0)$ & & \\
\hline Gombe & $0(0.0)$ & & \\
\hline Taraba & $0(0.0)$ & & \\
\hline Yobe & $0(0.0)$ & & \\
\hline
\end{tabular}

DOI: http://dx.doi.org/10.4314/ejhs.v29i3.13 


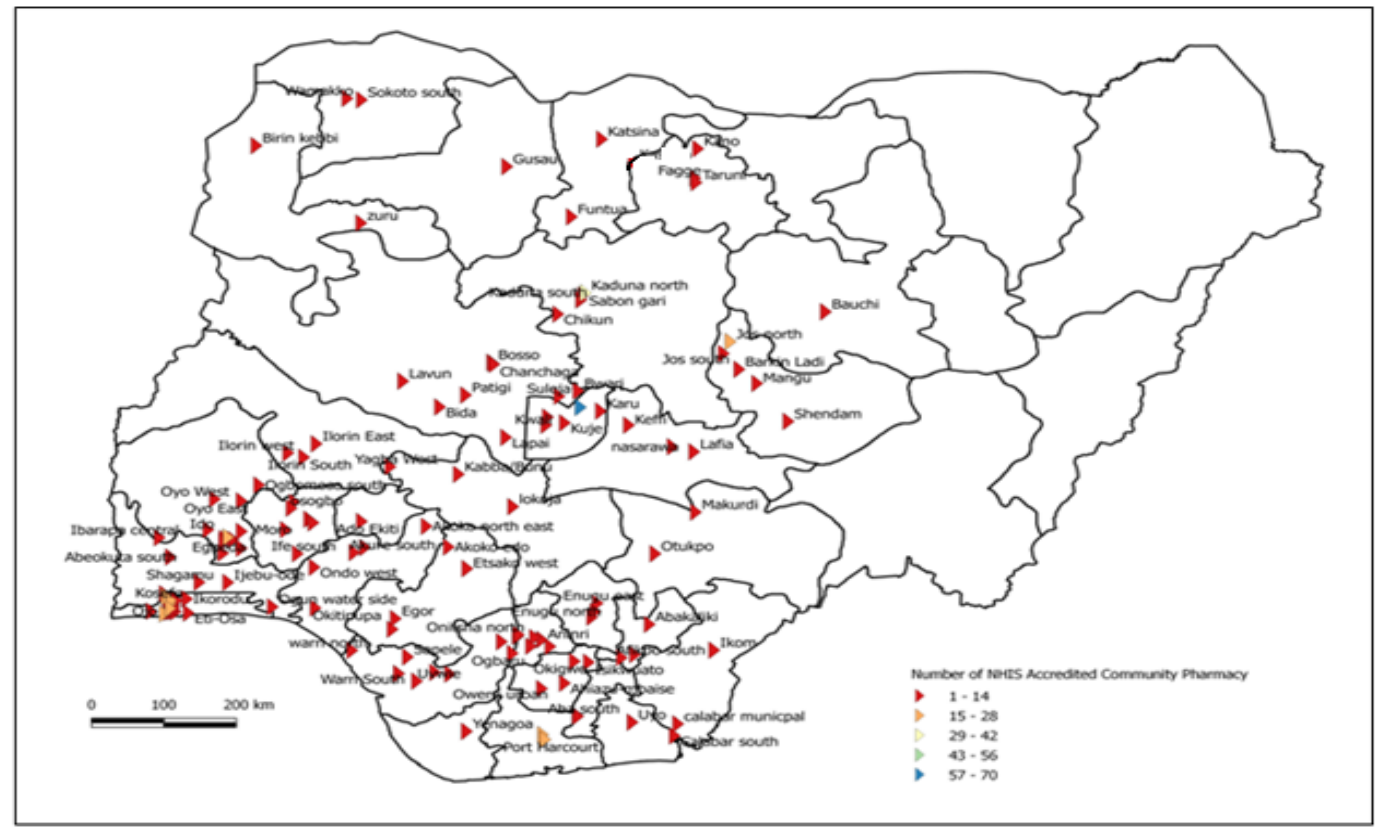

Figure 1a: Nigerian total number of NHIS accredited PRCPS by states Relative to LGAs

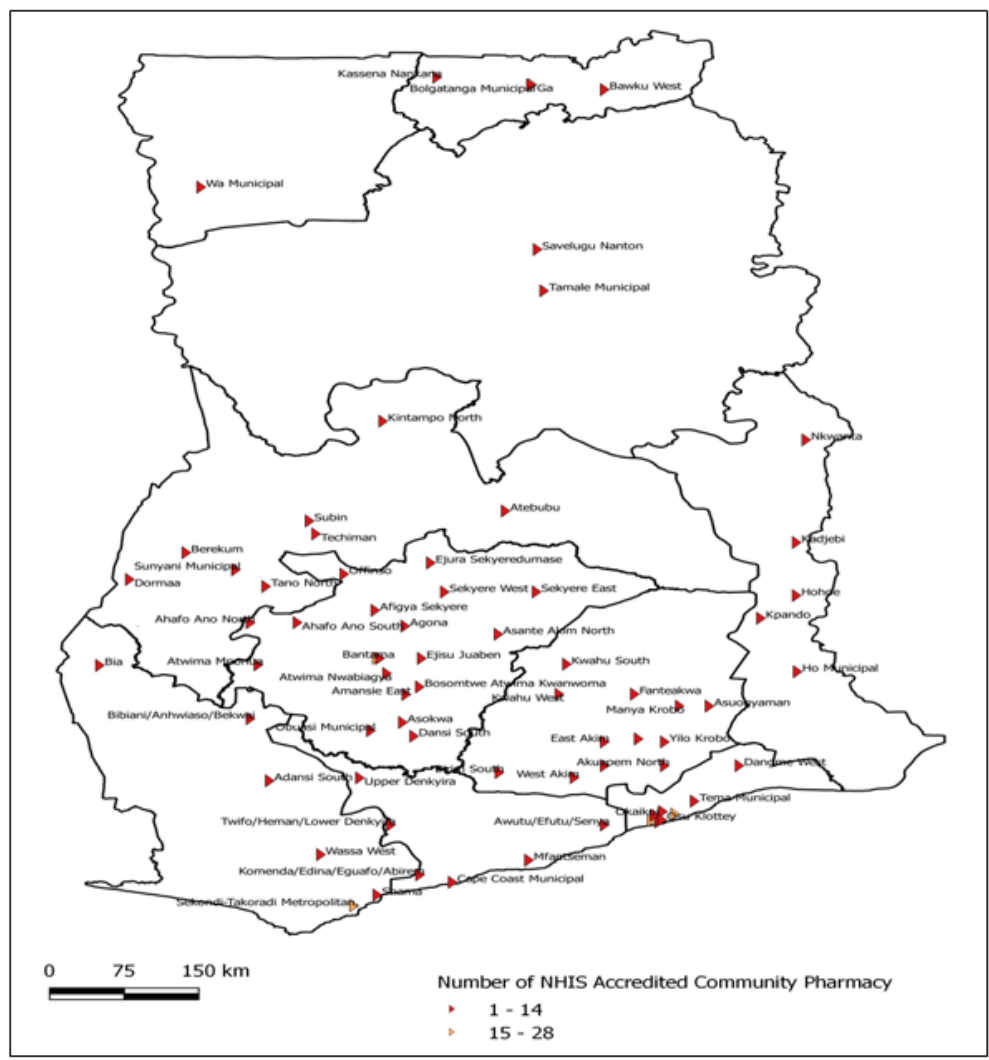

Figure 1b: Ghanaian total number of NHIS accredited PRCPs by region relative to MMAs

DOI: http://dx.doi.org/10.4314/ejhs.v29i3.13 


\section{DISCUSSION}

This study shows low participation of PRCPs in the NHIS of both countries. In Nigeria, the majority of the NHIS accredited PRCPs are located in the Lagos State, whereas in Ghana, most of them are found in the Greater Accra Region. Spatial distribution reveals skewed distribution with more accredited PRCPs found in the major cosmopolitan States or Regions and LGAs or MMAs of each country.

Even though Nigeria and Ghana have no standard number of pharmacies to a population as some other countries do, this study revealed that in Nigeria where accredited PRCPs are more relative to the NHIS population, one PRCP serviced 9,390 insured persons whereas, in Ghana, one PRCP still services 33,108 insured persons if evenly distributed. The higher NHIS population serviced by one accredited PRCP recorded for Ghana indicates lower participation of PRCPs relative to NHIS coverage in Ghana compared with the one in Nigeria. The present level of participation is still inadequate to ensure effective implementation of the scheme in both countries that will guarantee improved access to essential medicines. This thus calls for urgent attention. Many countries have legislation adjusting pharmacy distribution. These countries include South Africa (15) and Canada (16) which have 1 pharmacy per 10,000 people benchmarks, and Saudi Arabia (17) and Iran with 1 pharmacy per 6,000 people benchmarks (18).

However, despite constant availability of essential medicines from PRCPs (9) and a major benefit package of the provision of pharmaceutical care to insured patients by the pharmacists in these facilities, they remain underutilized in the scheme especially in Ghana that has higher coverage compared with Nigeria. Comparable with these findings, previous studies conducted in Nigeria and Ghana had reported low participation of PRCPs in the scheme $(8,19)$.

The plausible reason for this observation in Nigeria may not be unconnected with factors such as community pharmacist's poor knowledge, negative attitude and perception of Health Insurance Scheme (8). Another reason could be primary care providers being responsible for reimbursement of PRCPs for medicines dispensed under the scheme as against feefor-service payment method by HMOs as contained in the NHIS policy document. Lack of enforcement of separation of services of prescriber and dispenser could also be a contributing factor. Prescribers in the private sector health facilities simultaneously dispensing medicines is a common practice in developing nations. Consequently, it is only when the NHIS beneficiaries are not able to get the medicines they need directly from such private hospitals/clinics/maternity homes that they turn to PRCPs for medicines.

Against global best practices, private hospital/clinics and maternity homes dispense various classes of essential prescription medicines without employing a pharmacist due to poor regulatory and enforcement activities of the Pharmacy Council of Nigeria (PCN). As a result, prescriptions of these private hospitals/clinics and maternity homes no longer get to the PRCPs thereby depriving insured patients of the benefits of pharmaceutical services within their immediate communities. Contrary to this practice, in the United Kingdom, because of separation of services where physicians prescribe and the pharmacies dispense, the national health scheme has had a positive impact on community pharmacies (20). Furthermore, delay in reimbursement, tedious claim filling processes and delays in adjusting NHIS medicines price list to reflect prevailing market trends $(10,21)$, low prescription turnover, lack of separation of prescribing and dispensing services similar to the Nigerian situation have been identified as factors affecting the participation of PRCPs in NHIS of Ghana. Understanding of these factors will be useful to policymakers of the scheme to institute appropriate interventions that will ensure the sustainability of the scheme through private sector participation. However, if these factors are not urgently addressed, the sustainability of the scheme in terms of access to affordable essential medicines would be critically affected if more PRCP providers are unwilling to enroll or to remain in the scheme.

Poor accessibility, for example, can cause prescription to go unfilled thus leading to the irrational use of medicines. Therefore, geographical access to pharmacies is important to ensure access to essential medicines and related professional services. The spatial dimension to the analysis is occasioned by recent recognition that spatial data analysis techniques are vital skills required by the government of developing countries to meet the SDGs. Geographical distribution of pharmacies has implications for rural and deprived areas, and patients with decreased mobility.

Nigeria is divided into 36 States and Federal Capital Territory (FCT), which is further divided into 774 LGAs similar to Ghana with ten administrative/political regions, which are further divided into 254 MMAs. When the number of NHIS accredited PRCPs in Nigeria were analyzed by States relative to LGAs, it was found that Lagos State and Abuja Municipal Area Council have the highest number of NHIS accredited PRCPs among the State and LGAs respectively. Lagos State housed a

DOI: http://dx.doi.org/10.4314/ejhs.v29i3.13 
metropolitan city and was ranked as the second highest in the 2006 census (22). It was the former capital city of Nigeria and is still the business hub of Nigeria. Abuja Municipal Area Council is the highest cosmopolitan area council of the FCT. Hence, there is a drive for professionals to settle in this state and council area. These findings are consistent with the results of a similar study that appraised the distribution of pharmacists in Nigeria (23). In contrast, the North East States of Adamawa, Borno, Gombe, Taraba, and Yobe have zero PRCP participation in the scheme. These findings indicate geographically skewed distribution, suggesting that beneficiaries from these states are completely deprived of the benefits of pharmaceutical services within their immediate communities under the scheme. These results could also be attributed to the community pharmacist's poor knowledge, negative attitude and perception of Health Insurance Scheme earlier identified by a previous study (8). In the case of Ghana, Greater Accra and Ablekuma have the highest number of NHIS accredited PRCPs among the regions and MMAs. Contrary to the distribution pattern observed in Nigeria, no region in Ghana had zero participation of PRCPs in the scheme, but imbalance also exists with implications for access to essential medicines and pharmaceutical care to the poor rural dwellers.

Overall, even where NHIS accredited PRCPs are most concentrated, like other community pharmacies, they are mostly concentrated in urban centres leaving the rural areas underserved (23). Lack of improved social amenities in the rural areas (23), lack of rural incentives and the shortage of community pharmacists could account for the noted skewed distribution of NHIS accredited PRCPs in both countries. Hence, there is a need for targeted interventions to increase the presence of community pharmacies in the rural and remote areas to enhance availability and accessibility of essential medicines in the scheme through private sector participation using PRCPs in congruence with the objective of the scheme in ensuring equitable distribution of healthcare facilities within each country. This is in agreement with an earlier study (16) which recommended that governments should critically consider implementing strategies such as the provision of professional compensation for those pharmacists in rural and remote areas as applicable in Australia and Ontario (24). In view of this, if NHIS is properly executed in both countries, PRCPs has huge potential to meeting medicine and medicine-related needs of patients under the scheme thereby making essential medicines more available and accessible to the insured population. The only limitation of this study was that documented data on NHIS coverage in
2018 for both countries could not be found; hence, the last published coverage figures might not reflect the current coverage.

In conclusion, this study reveals low participation of PRCPs in the implementation of NHIS in both Nigeria and Ghana evidenced by high NHIS population per one PRCP if evenly distributed, although Nigeria had higher participation due to lower coverage attained by the scheme in the country compared with Ghana. A high number of these participating pharmacies are located in major cosmopolitan States or Regions/LGAs or MMAs of both countries. Based on the findings of this study, the following are implications for policymakers:

- It is the view of this study that policymakers of both countries should review pharmaceutical and health services policy to separate prescribing and dispensing services in tune with global best practices. This has huge potential for improving PRCPs participation in the scheme.

- The national health insurance authorities of both countries should institute appropriate interventions to address the issue of delay in payment of claims submitted by accredited PRCP to prevent them from running out of essential medicines.

- Fee-for-service payment policy through Health Maintenance Organizations (HMOs) for PRCPs in Nigeria as contained in the NHIS operational guideline should be enforced to secure community pharmacists satisfactions. Alternatively, PRCPs should be recognized as primary providers.

- There is a need to scale up and intensify community pharmacists education and awareness programme, especially in Nigeria to enlighten them on the positive pharmaceutical value of the scheme. Effective engagement of community pharmacists has the capacity to create a system that will enhance service delivery, and sustainability of the programme.

- The geographical distribution of PRCPs should be expanded through rural incentives to ensure that rural parts and deprived areas of Nigeria and Ghana attain the community pharmacy density levels that exist in urban zones. This expansion will enable enrollees in such remote areas to have unhindered access to essential medicines without having to travel to an urban zone to access healthcare services.

\section{REFERENCES}

DOI: http://dx.doi.org/10.4314/ejhs.v29i3.13 
1. Nwakeze NM, Kandal NB. The spatial distribution of health establishments in Nigeria. African Population Studies. 2011;25(2):680-696.

2. The World Health Organization: The world health report - Health systems financing: the path to universal coverage. Geneva: World Health Organization; 2010.

3. Government of the Federal Republic of Nigeria. Sustainable development Goals (SDGs) Indicators Baseline Report 2016. http://www.ng.undp.org/dam/nigeria/docs/ Accessed October 13, 2018.

4. Ghana SDGs Indicator Baseline Report http://www.gh.undp.org/ Accessed October 13, 2018.

5. The National Health Insurance Scheme, Nigeria Web site. http://www.nhis.gov.ng/ Accessed October 13, 2018.

6. National Health Insurance Scheme, Ghana Web site. http://www.nhis.gov.gh/?CategoryID=216. Accessed October 13, 2018.

7. Smith F. Community Pharmacy in Ghana: enhancing the contribution to primary healthcare .Health Policy and Planning. 2004;19(4):234-241

8. Okafor UG. Assessment of Knowledge, Attitude, Perception and Practice of Health Insurance Scheme among Community Pharmacies in Lagos State. Texila International Journal of Public Health. 2016;4(4):1-10.

9. Opoku BN. Public and private pharmacies in Bantama sub-metro: case study of Komfo Anokye teaching hospital and Nimo pharmacy limited in ashanti region [master's thesis]. Kwame Nkrumah University of Science and Technology, Kumasi, Ghana; 2015.

10. Adjei MA. The Impact of National Health Insurance on Community Pharmacies: A Case Study of the Western Region of Ghana. Ghana Medical Journal. 2012;46-51.

11. Accredited secondary healthcare provider https:/www.nhis.gov.ng/downloadabledocuments/ Accessed September 20, 2018.

12. National Health Insurance Scheme Providers http://www.nhis.gov.gh/providerinfo.aspx Accessed September 20, 2018.

13. Omomia O. Lack of mandatory participation in the NHIS Act Impending Growth of Health Insurance Coverage in Nigeria. Business Day. March 29, 2018. https://www.businessdayonline.com Accessed October 16, 2018.

14. Alhassan RK, Nketiah-Amponsah E, Arhinful DK. A Review of the National Health Insurance Scheme in Ghana: What Are the Sustainability
Threats and Prospects? PLoS ONE. 2016;11(11):e0165151.

15. Ward K, Sanders D, Leng H, Pollock AM. Assessing equity in the geographical distribution of community pharmacies in South Africa in preparation for a national health insurance scheme. Bull World Health Organ. 2014;92:482.

16. Law MR, Dijkstra A, Douillard JA, Morgan SG. Geographic accessibility of community pharmacies in Ontario. Healthcare Policy. 2011;6:36-45.

17. Najjar T. Study on the distribution of community pharmacies in Riyadh, Saudi Arabia. J Soc Adm Pharm. 2003;20:72-76.

18. Kebriaeezadeh A, Eslamitabar SH, Khatibi M. Iranian pharmaceutical law and regulations, 2nd ed. Razi distribution; 2008:199-206.

19. Ashigbie PG, Azameti D, Wirtz VJ. Challenges of medicines management in the public and private sector under Ghana's National Health Insurance Scheme-A qualitative study. Journal of Pharmaceutical Policy and Practice. 2016;9(6):1.

20. Tumwine Y, Kutyabami P, Odoi RA, Kalyango JN. Availability and expiry of essential medicines and supplies during the 'pull' and 'push' drug acquisition systems in a Rural Ugandan Hospital. Tropical Journal of Pharmaceutical Research. 2010;9(6):57-564.

21. Abugri A. Impact of NHIS on the performance and financing of Government Hospitals. The case of Hospitals in Kumasi Metropolis [master's thesis]. Kwame Nkrumah University of Science and Technology, Kumasi, Ghana; 2010.

22. Population by State and Sex; 2006. http://www.population.gov.ng/index.php/statepopulation. Accessed October 16, 2018.

23. Oseni YO, Oseni YO. Pharmacists' distribution in Nigeria; implication in the provision of safe medicines and pharmaceutical care. Int $J$ Pharm Pharm Sci. 2017;9(10):49-54.

24. Mossialos E, Mrazek M, Walley T. Regulating Pharmaceuticals in Europe: striving for efficiency, equity and quality. Maidenhead (UK): McGrawHill International; 2004.

DOI: http://dx.doi.org/10.4314/ejhs.v29i3.13 